\title{
Advantages and Challenges of Smart Learning in Higher Education Institutions in Saudi Arabia
}

\author{
Amer N. Fayez, Fahad M. Ghabban, Omair Ameerbakhsh \\ College of Computer Science and Engineering, Information System department, Taibah University, Madinah, Saudi Arabia \\ Email: Fghaban@taibahu.edu.sa
}

How to cite this paper: Fayez, A. N., Ghabban, F. M., \& Ameerbakhsh, O. (2021). Advantages and Challenges of Smart Learning in Higher Education Institutions in Saudi Arabia. Creative Education, 12, 974-982.

https://doi.org/10.4236/ce.2021.125071

Received: April 26, 2021

Accepted: May 21, 2021

Published: May 24, 2021

Copyright ( 2021 by author(s) and Scientific Research Publishing Inc. This work is licensed under the Creative Commons Attribution International License (CC BY 4.0).

http://creativecommons.org/licenses/by/4.0/

\begin{abstract}
Higher Education Institutions have been implementing a unique technology-based learning way, as Information and Communication Technology is rapidly growing. Smart Learning is technology-supported learning that provides a comfortable learning environment that touches the individual learners' needs. The new learning platform seeks to enhance education in a more intelligent yet simpler way. As this topic becomes a global educational matter, the Saudi government has been carefully discussing the implementation of Smart Learning since 2007. This research paper studies the advantages and challenges that will face the students by implementing a Smart Learning environment in Higher Education Institutions in Saudi Arabia. This research is completed using Quantitative research methodology. It develops questionnaire and applies to 530 students and professor in Saudi universities. This study comes with benefits and challenges of e-learning such as flexibility, interaction and internet experience. Also, it suggests a set of innovative recommendations to overcome the challenges that the Saudi universities might face with the new learning system.
\end{abstract}

\section{Keywords}

Electronic Learning, Smart Learning, ICT, Learning Environment, Higher Education Institutions

\section{Introduction}

The education nowadays is becoming technology-based especially with the current pandemic. Smart learning is the new intelligent education that is spreading around the world and is achieving great results in most countries. Information and Communication Technologies (ICT) have helped in developing the Smart 
Learning system as they transformed the current methods for education into more interactive and visualizable means. The use of information and communication technology also re-shapes some aspects of cultures and societies. According to the research paper "Evolution is not enough: Revolutionizing current learning environments to smart learning environments", Smart Learning integrates formal and informal learning to create an adaptive learning environment for supporting individuals with real-time and seamless experiences (Chen et al., 2016). In Saudi Arabia, Smart Learning has been rapidly growing in the past few years and the Saudi education sector is moving towards the new system through electronic devices, which phones and computer devices are used for communication purposes among teachers, instructors, and students (Siemens, 2013). The higher education in Saudi Arabia has been changing to a more internet-based education accompanying the rapid development of information technology including software and hardware devices (Alajmi et al., 2017).

(Peters \& Araya, 2011) Smart Learning should be available via mobile or computer devices in order to use information communication technologies for higher education. The combination of using wireless network and smart devices establishes a unique platform for easing and simplifying the education learning process. Students can simply access digital data given by instructors and professors though their devices, and therefore, creating a comfortable and easy way of learning, and it will give students some flexibility to get back to the data anytime they want (Peters \& Araya, 2011). In addition to that, Smart learning can reach its full potential in higher education if proper interactive methods between professors and students are implemented.

On the other hand, Smart learning can have limitations that will hinder the learning process. As smart learning or E-learning relies on having access to the internet and electronic devices, the absence of either of them will create a huge issue to students. Thus, the use of smart learning was restricted by the currently available infrastructures of learning elements and maintenance in Saudi Arabia (Xanthidis et al., 2013). This research paper studies the advantages and challenges that will face the students by implementing a Smart Learning environment in Higher Education Institutions in Saudi Arabia. It is means this study aims to present the benefits and challenges faced by students and their professors during the heavy use of e-learning. This finding will support the Saudi higher education to face any future pandemic.

\section{Literature Review}

Education has been changing over the past years as technology keeps advancing with new systems and models. Throughout the last decade, the intelligent education, known as Smart Learning, has been implemented in most developed countries and some developing countries using Technology-enhanced learning (TEL). This type of learning enables easy access to academic contents, communication inquiry, and evaluation of studies (Alajmi et al., 2020). In developing 
countries, the use of TEL has been extremely beneficial especially that smart devices such as mobile phones and computers are in hands with the majority of people.

The emergence of Smart Learning comes from using different technologies as cloud computing, learning analytics or big data. According to (Gros, 2016) the use of those technologies focuses on how learning data can be captured, analyzed and directed towards improving learning and teaching, and supporting the development of personalized and adaptive learning (Gros, 2016). Cloud computing allows learners to access the learning material anytime they want, Big data enhances the learning and teaching techniques, and learning analytics helps learners in understanding and optimizing learning with the different environments that it occurs (Tsai, 2020). Thus, the growth of Smart Learning is important to make education more flexible and easier to learners.

In Saudi Arabia, the emergence of E-learning has started in 1954 1-Imam Muhammad Ibn Saud Islamic University initiated a distance-learning program in the Faculty of Religious Science, and a year later in the Faculty of Arabic Language (Alturki, 2014). Saudi Arabia took all the responsibility for providing the necessities of e-learning such as internet access, electricity, and other needed services.

\section{Background of the Study \& Objectives}

As is still growing in Saudi Arabia, many researchers still have a few concerns regarding that educational system. Some of those concerns are: how does Smart Learning balance the focus between learners, teachers, and learning data, and the devices used? How advanced should the information communication and technology be in a country to achieve the optimal results of Smart Learning? What is the right balance between E-Learning and real-life learning?

As these concerns are still unclear, there is still a main issue regarding implementing Smart Learning. Technology plays an important role to support Smart Learning environment and reach its full potential. Smart Learning should not only emphasize the use of smart devices, but also it should focus on applying social and real-life learning. Smart learning mainly reflects how advanced technologies are to allow learners to absorb knowledge, information, and skills more effectively, efficiently and conveniently through mobile devices (Al Awar, 2021). Those devices are utilized to achieve the Smart Learning techniques such as formal and informal learning, personalized and positioned learning, and social and collective learning. Therefore, the shift from traditional learning to Smart Learning face several challenges in developing countries such as Saudi Arabia, and the perception of the student, teachers, and service providers on smart learning is quite little (Picciano, 2012).

Therefore, this research seeks to find innovative methods in using information and technology in the Saudi higher education learning. There are two questions should be answered in order to give optimal suggestions regarding smart learn- 
ing environment for higher education students in Saudi Arabia: What are the advantages of Smart Learning for students? And what are the challenges and solutions for students in the new learning environment in Saudi Arabia?

The following is the methodology taken to recognize the advantages of implementing technology-enhanced learning and the challenges that the Saudi college students will face as a result of applying Smart Learning. As well as, identifying the solutions for the given challenges.

\section{Research Methodology}

This research is completed using Quantitative research methodology, known as Descriptive research. According to (QuestionPro, 2021) the definition of Descriptive research is "that attempts to collect quantifiable information for statistical analysis of the population sample. It is a popular market research tool that allows us to collect and describe the demographic segment's nature (QuestionPro, 2021). The reason why this method is employed is to show the relationship between the research objective and the existing characteristics such as population, current methods of communicating between professors and students.

The targeted population includes higher education professors and students in Saudi Arabia, especially those who are experiencing Smart Learning. They were invited to participate in the study to provide statistics regarding the research topic. In addition to that, some random participation was conducted to other students and professors.

\subsection{Research Methods}

Two research methods were taken to gather data for the study: Quantitative approach, and inductive approach. Quantitative approach was used to for data collection and analysis. The data must be expressed in numerical form in order to analyze it. Then, the inductive research approach was used to generate theories from the data collected (Libraries, 2021).

\subsection{Data Collection}

(Al-Harbi, 2011) the purpose of the questionnaire is to determine any relationships between the targeted audience knowledge of E-learning and their demographics such as gender, type of learning, their background, and type of internet connection (Al-Harbi, 2011). This questionnaire also helps to show the acceptance of students to the new learning system. 530 individuals, including students and professors, participated in the questionnaire from King Abdul Aziz University in Jeddah, Saudi Arabia. Table 1, Table 2 shows the results obtained:

According to Table 2, the majority of professors and students has a medium to high experience on the Internet; it was around $79 \%$ with experience. This is not surprising since the respondents are at a university, and the use of Internet is kind of essential. Only around 3\% of the respondents chose no Internet experience. Experience in the internet. 
Table 1. Gender and type or learning.

\begin{tabular}{cccc}
\hline & Gender & \multicolumn{2}{c}{ Type of Learning } \\
\hline Male & Female & Traditional & Long Distance \\
\hline 209 & 321 & 447 & 83 \\
\hline
\end{tabular}

Table 2. Professors and student's experience in internet.

\begin{tabular}{ccc}
\hline \multicolumn{3}{c}{ Experience in Internet } \\
\hline No Experience & Medium Experience & High Experience \\
\hline 14 & 216 & 201 \\
\hline
\end{tabular}

Table 3 shows the kind of Internet connection that the professors and students used. More than half of the sample, around 54\% used the DSL connection, and this kind offers the strongest connection of all. Whereas only $3.4 \%$ of the sample used Satellite connection perhaps due to its high expense. From the sample, there is 10 respondents who did not have any type of the internet connection, which is about $2 \%$ of the sample.

\subsection{Research Questionnaire}

The questionnaire contains three sections. According to (Al-Harbi, 2011), the first section collected information about the students' Internet experience and self-efficacy, the second section elicited information on their perceptions and attitude toward e-learning, and the third one gathered some demographic information (Al-Harbi, 2011). This survey was inspired by previous researchers, and the scale used was a 7-point Likert scale, where 1 is strongly disagree, 7 is strongly agree, and 4 is undecided (Ajzen, 1985; Moore \& Benbasat, 1991; Wu et al., 2003).

\section{Data Analysis}

According to the study, it suggested a model in order to further explain the Saudi students' intentions in accepting of the use of e-learning. (Ajzen, 1985) theory of planned behavior found that attitude is an important factor that affects the student's intention in using of e-learning. This means that students who tend to have a favorable attitude towards using e-learning are more inclined to use e-learning in their study (Ajzen, 1985). Not only that, but it also shows the importance of the influence of instructors and professors in the topic. Another factor that affects the student's intention is the subjective norm, as well as other factors such as self-efficacy, and perceived e-learning accessibility. According to (Al-Harbi, 2011) the data collected also showed that the students' intentions (BI) may be influenced by their confidence with using the internet to adopt e-learning in their study. This means that students, who are experienced in using the Internet, will find the shift from the traditional learning to e-learning easier. Table 4, Table 5 shows the regression results for PU and comparisons between students. 
Table 3. Types of internet connection used.

\begin{tabular}{ccccc}
\hline Dial up & DSL & Satellite & Mobile & No connection \\
\hline 187 & 287 & 18 & 29 & 10 \\
\hline
\end{tabular}

Table 4. Regression results for PU.

\begin{tabular}{ccccc}
\hline & $\mathrm{B}$ & Std. Error & $\beta$ & $95 \%$ CI for B \\
\hline Perceived Interactivity & .357 & .035 & $.383^{* * *}$ & $.289-.426$ \\
Perceived Flexibility & .396 & .036 & $.428^{* * *}$ & $.326-.465$ \\
Internet Experience & .046 & .024 & .060 & -.002 to .094 \\
\hline
\end{tabular}

Note: $\mathrm{R} 2=.56 \mathrm{CI}$ : Confidence Interval; ${ }^{* *} P<.001$.

Table 5. Comparisons between students.

\begin{tabular}{cccccc}
\hline Variable & $\mathrm{M}$ & $\mathrm{SD}$ & $\mathrm{t}$ & $d f$ & $p$ \\
\hline BI & & & & & .002 \\
Males & 5.54 & 1.17 & 3.09 & 528 & \\
Females & 5.19 & 1.28 & & & .503 \\
BI & & & & 520 & \\
Jeddah & 5.31 & 1.28 & -.67 & & \\
Outside & 5.39 & 1.17 & & & \\
BI & & & & & \\
Regular & 5.25 & 1.28 & 4.782 & 157.602 & \\
External & 5.85 & .91 & & & \\
\hline
\end{tabular}

2 The $t$ and $d f$ were adjust because variance were not equal.

One of the determinants that this model suggested was university support (US). From the analysis of the questionnaire, it was found that the university support had a great impact on the implementation of e-learning in their programs. This main determinant correlated to the students' confidence with using the new technology. With more support coming from the university, students would feel more comfortable using the services that e-learning offers such as long-distance learning and fast communication between instructors and students.

Furthermore, the study found that gender plays an important role in the use of e-learning. When talking about Saudi Arabia, gender should be discussed and how it can certainly be a factor that may influence the implementation of e-learning. This study showed that Saudi male tends to be more acceptable to use of e-learning than the Saudi female students.

\section{Discussion}

\subsection{Benefits of E-Learning}

The use of e-learning in higher education offers more flexibility to students than 
the traditional learning. Being able to access the educational materials anytime the student wants, and as many times as they want, will make the education process easy for them. This benefit can be for the external students in a college. According to (Al-Harbi, 2011) the external students were attracted to the use of e-learning due to the flexibility that it offers to them. Another benefit that the e-learning offers is the fast communication between the professors and students (Al-Harbi, 2011). Since it is an internet-based learning, it is easy to communicate with one another whether a phone call, video call, or even emails. E-learning provides various means to communicate which will make it easier for external students specifically.

\subsection{Challenges of E-Learning}

The main challenge of e-learning is the ability to access materials and exercises from portable devices such as mobile phones and laptops. Advanced technologies need to be accessible to all students in order to eliminate any barriers and enhance the education efficiency (Klašnja-Milićević et al., 2018). The challenge is to provide such devices to all students to allow them to get the benefit of e-learning. This can be hard to achieve because not every household in Saudi Arabia is capable of providing such devices to their children. Additionally, in order to incorporate such devices, it is essential to create new methodological improvements to instructional materials (Al Shami et al., 2019). This brings the other challenge that might face the implementation of e-learning. Instructors should create a complete online-based material that can fulfil the e-learning goal.

\subsection{Solutions to the Challenges}

As Saudi Arabia is rapidly growing in terms on technology and economy, one of the solutions might be that the Saudi government subsidizes universities with sufficient funds to provide all the necessity for e-learning. This is a huge step, but it is extremely beneficial to ease the transition to e-learning in their educational system. Furthermore, training courses on how to use-learning are important for students who do not feel comfortable to adjust to the new educational system. Those courses can cover the basis of e-learning and the best way to get the full experience using e-learning.

\section{Conclusion}

This research paper focused on determining the factors that affect the Saudi students' intention to use e-learning. The data collected showed that the acceptance of e-learning depends on several factors such as accessibility, gender, confidence, subjective norm, and attitude. The results suggested that the students' attitude toward smart learning is the most important factor in showing the students' intention in e-learning. The students' intention was also shown by their subjective norm, which means how people around them can affect their decisions. That is related to the students' confidence with using e-learning and their acceptance to 
the new educational system. Furthermore, e-learning accessibility takes a major part in the implementation process of e-learning, which is influenced by the university support. Finally, the students showed variation in their intention to use e-learning based on their gender. Male and external students expressed a stronger intention that the rest of the students due to the benefits that they can get from e-learning.

\section{Conflicts of Interest}

The authors declare no conflicts of interest regarding the publication of this paper.

\section{References}

Ajzen, I. (1985). From Intentions to Actions: A Theory of Planned Behavior. In J. Kuhl, \& J. Beckmann (Eds.), Action Control (pp. 11-39). Berlin, Heidelberg: Springer. https://doi.org/10.1007/978-3-642-69746-3_2

Al Awar, M. (2021). Pioneering Smart Learning. Ellucian. https://www.ellucian.com/emea-ap/insights/pioneering-smart-learning

Al Shami, E., Zhang, R., \& Wang, X. (2019). Point Absorber Wave Energy Harvesters: A Review of Recent Developments. Energies, 12, 47. https://doi.org/10.3390/en12010047

Alajmi, Q., Al-Sharafi, M. A., \& Abuali, A. (2020). Smart Learning Gateways for Omani HEIs towards Educational Technology: Benefits, Challenges and Solutions. International Journal of Information Technology and Language Studies, 4, 12-17.

Alajmi, Q., Sadiq, A., Kamaludin, A., \& Al-Sharafi, M. A. (2017). E-Learning Models: The Effectiveness of the Cloud-Based E-Learning Model over the Traditional E-Learning Model. 2017 8th International Conference on Information Technology (ICIT), Amman, 17-18 May 2017, 12-16. https://doi.org/10.1109/ICITECH.2017.8079909

Al-Harbi, K. A.-S. (2011). E-Learning in the Saudi Tertiary Education: Potential and Challenges. Applied Computing and Informatics, 9, 31-46. https://doi.org/10.1016/j.aci.2010.03.002

Alturki, U. T. (2014). The Development of Online Distance Education in Saudi Arabia. eLearn, 2014, Article No. 5. https://doi.org/10.1145/2687917.2673861

Chen, N.-S., Cheng, I.-L., \& Chew, S. W. (2016). Evolution Is Not Enough: Revolutionizing Current Learning Environments to Smart Learning Environments. International Journal of Artificial Intelligence in Education, 26, 561-581. https://doi.org/10.1007/s40593-016-0108-x

Gros, B. (2016). The Design of Smart Educational Environments. Smart Learning Environments, 3, Article No. 15. https://doi.org/10.1186/s40561-016-0039-x

Klašnja-Milićević, A., Ivanović, M., Vesin, B., \& Budimac, Z. (2018). Enhancing E-Learning Systems with Personalized Recommendation Based on Collaborative Tagging Techniques. Applied Intelligence, 48, 1519-1535. https://doi.org/10.1007/s10489-017-1051-8

Libraries, U. (2021). Quantitative Methods. Los Angeles, CA: University of Southern California. https://libguides.usc.edu/writingguide/quantitative

Moore, G. C., \& Benbasat, I. (1991). Development of an Instrument to Measure the Perceptions of Adopting an Information Technology Innovation. Information Systems Research, 2, 192-222. https://doi.org/10.1287/isre.2.3.192

Peters, M. A., \& Araya, D. (2011). Transforming American Education: Learning Powered 
by Technology. E-Learning and Digital Media, 8, 102-105.

https://doi.org/10.2304/elea.2011.8.2.102

Picciano, A. G. (2012). The Evolution of Big Data and Learning Analytics in American Higher Education. Journal of Asynchronous Learning Networks, 16, 9-20. https://doi.org/10.24059/olj.v16i3.267

QuestionPro (2021). Descriptive Research: Definition, Characteristics, Methods, Examples and Advantages. QuestionPro.

https://www.questionpro.com/blog/descriptive-research/

Siemens, G. (2013). Learning Analytics: The Emergence of a Discipline. American Behavioral Scientist, 57, 1380-1400. https://doi.org/10.1177/0002764213498851

Tsai, Y.-S. (2020). Learning Analytics in a Nutshell. http://yi-shan-tsai.com/index.php/2019/10/12/learning-analytics-in-a-nutshell/

Wu, I.-C., Ke, H.-L., Lo, Y.-C., Yang, Y.-C., Chuang, C.-H., Yu, F.-J., Lee, Y.-C., Jan, C.-M., Wang, W.-M., \& Wu, D.-C. (2003). Evaluation of a Newly Developed Office-Based Stool Test for Detecting Helicobacter Pylori: An Extensive Pilot Study. $\mathrm{He}$ pato-Gastroenterology, 50, 1761-1765.

Xanthidis, D., Wali, S. W., \& Nikolaidis, P. (2013). E-Learning in Saudi Universities, Challenges and Issues. 2013 Fourth International Conference on E-Learning Best Practices in Management, Design and Development of e-Courses: Standards of Excellence and Creativity, Manama, Bahrain, 7-9 May 2013, 473-478.

https://doi.org/10.1109/ECONF.2013.72 